\author{
Namir G. Ahmed Alkawaaz \\ E-mail: dr.namir@gmail.com \\ Noor Moutaz Asmael \\ E-mail: noor_moutaz@uomustansiriyah.edu.iq \\ Highway and Transportation Engineering Department, Faculty of Engineering, \\ Mustansiriyah University, Baghdad, Iraq
}

\title{
An Origin-Destination Matrix Estimate for Baghdad City Based on GIS
}

\begin{abstract}
Baghdad suffers a deficiency in the application of urban transportation planning process, especially in selecting the suitable transport policies to solve transportation problems. One of the important inputs to the transportation planning process is the Origin - Destination Matrix. The O-D matrix is the travel demand between the pair of origin and destination zones and is one of the necessary goals of transportation studies. Estimation of an O-D matrix using the conventional process requires the collection of a huge amount of data. In Baghdad city, there has been no O-D matrix formulated. Accordingly, a prior O-D matrix is estimated in this study. The present research methodology is based on the estimated O-D matrix for Baghdad city in 1987 (prior matrix) and then updated to 2014 using the collected traffic count data as the basis for travel forecasting. The results of this study provide a guide to the local transportation agencies to select the right transport policies, maximize their revenue and better allocate their resources.
\end{abstract}

Keywords: Travel demand modeling, O-D matrix, GIS, Transportation planning, TransCad

\section{Introduction}

The Baghdad Governorate is the most populated area in Iraq, which has been growing rapidly since the late seventies and the annual growth has reached a double rate. The car ownership rate in Baghdad has been increasing and has thus increased traffic congestion and minimized the quality of traffic operation. To figure out this problem, it is necessary to accomplish up to date comprehensive transportation planning for 
Baghdad city, through detailed investigation of up to date home interview survey, and reliable traffic count that will assist to investigate the existing travel characteristics. Today, the trip rate is expected to be different and higher than shown by the latest studies due to high economic change, high car ownership and high in trip demand. Such investigation will assist in introducing urban rail transit and will produce integrated public transport. Based on the available information from the related local agencies, there has been a deficiency in the application of a transportation planning process since the end of the eighties. Such a deficiency in the application of an efficient transportation planning process in developing countries like Iraq will lead to bad transport policies to overcome the transportation problems. Accordingly, it is important to select transport policies and transportation projects based on Travel demand modeling. Transportation needs to analyze the existing traffic situation and project the future traffic; then a modification to the transit transport and changes in transport policies and patterns are recommended.

One of the important inputs to the transportation planning process is the Origin - Destination Matrix. The O-D matrix is considered the basis for the transportation planning analysis and it helps in constructing strategic transportation projects for long range planning. The $\mathrm{O}-\mathrm{D}$ matrix acts as a travel demand between any two zones. Estimation of an O-D matrix using conventional process requires collection of a huge amount of data. The data collected include socioeconomic, demographic, land use, and network characteristics. The O-D matrix estimated from traffic count mitigates the problem of collecting huge amounts of data required by conventional process. Traffic volume counts are already available and can be obtained easily. Many proposed models are presented to investigate the O-D matrix estimated from traffic count. One of these models is the TransCAD Model based on Nielsen's model [11], [4]. Nielsen's model is a bi-level process that switches between the traffic assignment and O-D matrix estimation. Nielsen's model requires the prior O-D matrix, Traffic Analysis Zone (TAZ), and highway network. In Baghdad city, no prior O-D matrix found. Accordingly, a prior O-D matrix was estimated in this study.

The implementation of the proposed methodology in the present study is to explore the existing travel characteristics of the study area, to estimate a prior O-D matrix, and to develop an O-D trip matrix based on a reliable traffic count using Nielsen's model.

\section{Background}

The origin - destination matrix is essential part in urban transportation planning, it is the process, which leads to decisions on transportation policies for long range planning. An origin-destination (O-D) matrix contains flows between each origin and destination; it is a necessary input to the transportation analysis such as traffic assignment. A (O-D) trip matrix is estimated from traditional surveys like license plate surveys, home interview survey, roadside surveys, etc. Such surveys are time 
consuming, expensive and labor intensive (Lei 1998) [10]. A survey of this kind has become harder to perform and expensive. It consumes man power, money and effort. The O-D matrix estimated from traffic count mitigates this problem. There has been a sufficient amount of literature found on different methods for estimating O-D matrix from traffic counts. Some of these works are presented here.

Verma and Dhingra [17] developed a model for identifying a demand-urban rail transit corridor using GIS tools. The new proposed model consists of four stages: generation of base year O-D person trip matrices, base travel demand modeling, forecasting of O-D person trip matrices, and identification of the rail transit corridor. The objective of the study is to select the new rail transit, which optimizes both the user's and operator's points of view. Novačko, Šimunović, and Krasić [13] applied a classical four step model for small cities. An initial origin-destination matrix created using traffic count data and the fuzzy logic was applied to correct the initial trip matrix. Ekowicaksono, Bukhari, and Aman [7] used the gravity model to estimate the O-D matrix for Bogor city. The O-D matrix is estimated based on two assumptions which are i) the force between zones which is related to socioeconomic characteristics and ii) movement of people which is influenced by the accessibility between the origin and destination. Anderson [2] used a methodology to estimate the origin/destination matrix from the existing traffic count, which will be subsequently used to generate the truck trip generation models. The model here presented as a case study applies to one smaller urban community. Holguín-Veras, Sánchez-Díaz, and González-Calderón [9] developed a framework to estimate O-D matrices from the traffic volume count with reduced cost and good accuracy that will help transportation management agencies in decision-making. Reza Tolouei, Pablo Álvarez [16] studied mobile phone data as a source of data for the development of highway matrix. They found a strong relationship between the demand derived from mobile phone data and conventional data and the differences appear to be acceptable. Nielsen and Hansen [12] used different data sources to estimate travel matrices, these include cordon line surveys, telephone survey data and the existing transport surveys. The base matrices were constructed and traffic counts used to adjust these matrices. Chen et al. [6] developed strategies for improving estimation of $\mathrm{O} / \mathrm{D}$ matrices by selecting additional traffic counts; the O-D matrix was estimated by utilizing a modified path flow estimator. Yang et al. [19] estimated the congestion O-D matrix by using a user-equilibrium assignment in the form of utilizing a bilevel optimization problem. Almasri and Al-jazzar [1] applied the traffic demand forecasting for the Gaza Strip. In this study, a model to estimate the O-D matrix is developed based on the traffic count. The results have been obtained from the Trans CAD software assigned to the study area (Gaza) maps using the spatial analysis based on GIS techniques. Therefore, an improvement scenario of the area was carried out. Wu, Shen, and Lv [18] proposed a method that formulates the relationship between the transit ridership and zonal population, employment, transit service level, and so on. In addition, the difference between transit counts and estimates for the base year are considered in the development of the transit O-D for the coming year. It is expected to 
perform better than conventional models in terms of transit network evolutions. Hamad and Faghri [8] present a new approach for implementing transportation planning studies in developing countries. The new model starts by calculating the (O-D) trip table based on traffic counts. After that, a modified origin-destination trip table is estimated from a simple new procedure before the application of the traffic assignment. Cascetta [5] proposed the use of generalized least squares to estimate the O-D matrix, combining with direct or model estimators with traffic counts by an assignment model. He observed that the variance of an O-D matrix estimated by generalized least squares is lower than by direct or model estimators.

\section{Methodology}

The latest efficient application of the transportation planning process for Baghdad city took place at the end of the seventies and eighties respectively by (Swiss Consultant - De Consul 1976) [15] and (Scott Wilson and Partners 1986) [14]. The forecasted travel data of these studies were out of date. It is important for transportation investment decisions to be arranged on the basis of the transportation planning process. Accordingly, it is important to have the travel demand updated to the current year. Due to limited data available, the research methodology of this study is based on the travel demand model of 1976 developed by Asmael [3]. The travel demand model of 1976 is considered the base for the current planning; the 1976 model was built based on the huge amount of reliable data collected by Swiss Consultant - De Consul. The 1976 model is valid for 25 years and accordingly it was used to generate the 1987 travel demand model. The current approach uses the original model of 1976 with an update concerning the planning variables to obtain an O-D matrix for 1987. The base year model of 1976 with its equations and parameters was proposed to be used as the base in modeling future year conditions in 1987 by updating demographic, socioeconomic and network input data. Because of survey difficulties, the O-D matrix estimation from the traffic volume has been adopted. The research methodology is based on a 1987 O/D matrix estimated (prior matrix) and reliable traffic count data which will be used as the base in the travel forecasting to estimate the O/D matrix in 2014.

\section{Estimation of the O-D matrix trip for 1987}

\subsection{Traffic Analysis Zones}

Zoning of Baghdad city is an important input to estimate the O-D matrix. Baghdad city is divided into Traffic analysis zones (TAZ), each to denote a geographic area where the trip has either the origin or destination. TAZ created in Trans CAD; TAZ of 1987 year is different from that of 1976. It included areas where urban development occurred within the Mayoralty of Baghdad (MoB); TAZs have been updated and divided into 187 zones. Figure (1) shows the TAZs for the travel demand model 1987. 


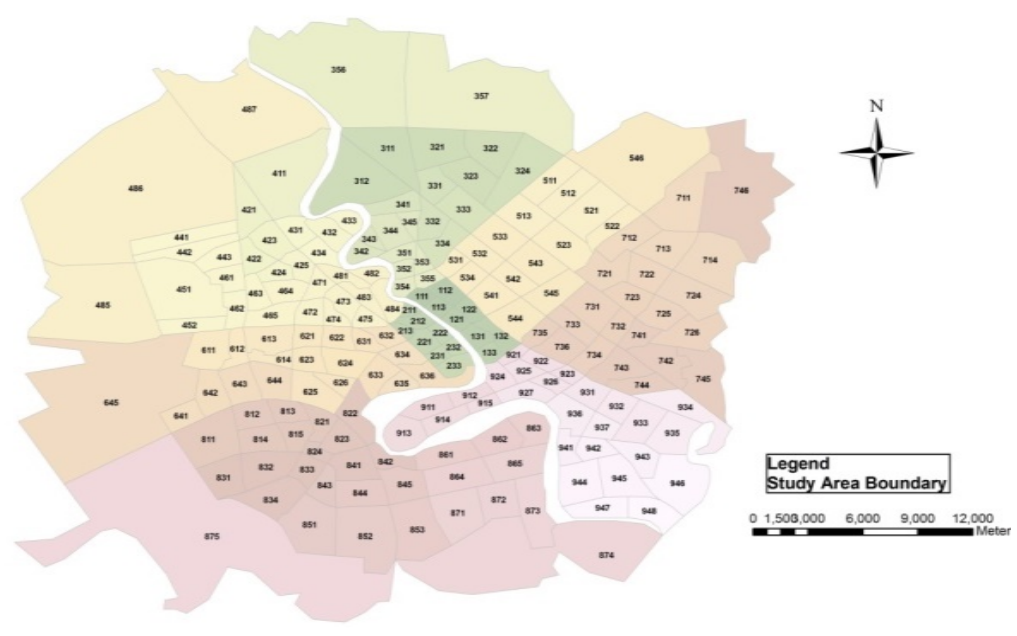

Figure 1 - TAZs for the travel demand model 1987

\subsection{Socioeconomic Data Preparation}

The Mayoralty of Baghdad covers an area of $840 \mathrm{~km}^{2}$ and a population of 3.840 .746 in 1987, which represents $80 \%$ of the Governorate population. The Census of 1987 was a real census carried out along the Mayoralty of Baghdad boundary; it represented relatively accurate information about the current socioeconomic context of Baghdad. Developing the 1987 model required collecting, coding, and using transportation related data to present accurate travel conditions. Population and Housing Census data for 1987 were collected from the Central Organization for Statistics and Information Technology. The socioeconomic characteristics consist of determining the population, households, employment, car ownership and income as distributed across TAZs. The Arc GIS were used in preparing thematic maps based on socioeconomic characteristics of the zones.

\subsection{Trip Generation Application}

Travel projection was developed using the forecasted land use and the future roadway network in 1987. To determine the forecasted production and attraction of each zone, the trip generation equations developed in 1976 by Asmael [3] are used as follows: 
The trip production model $=-2.33-0.174 * \mathrm{hh}$ size $+0.005 *$ Income $/ \mathrm{hh}+$ $1.713 *$ Car/hh $+6.417 *$ Exp. Employment Rate

Trip Attraction Model $=-244.9+1505.74 *($ Employment No./1000)

These equations are used with updated planning variables to generate the travel projection. Trips are estimated at the household level and then aggregated to the zone level. Figure (2) shows the trip generation results. The final output table will display the balance of total productions and attractions for each TAZ, which are used in the trip distribution gravity model.

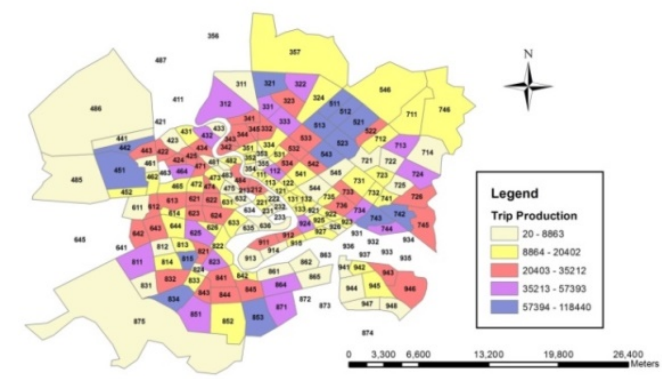

(a)

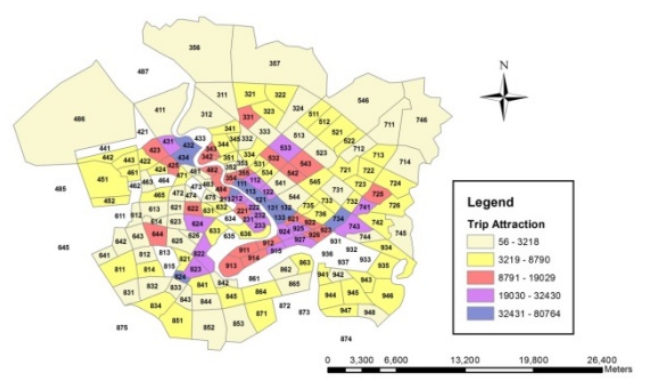

(b)

Figure 2 - Trip generation results, (a) Trip production, (b) Trip attraction 


\subsection{Trip Distribution Application}

Trip distribution is the next step in the four-step modeling process. In this step, the number of trips generated in the trip generation step is distributed among TAZ; to execute this process, the travel impedance (generally the function of travel time and/or cost) and P-A trips between TAZs are required. The building and updating of the Baghdad City road network were conducted using the Arc GIS and Trans CAD transportation planning software. The highway network was coded in the Trans CAD software version 4.5; basic elements of a network are nodes and links. Links refer to actual highways (excluding most minor local roads) found in the highway network. Nodes are end points of links and they connect links together. Nodes are usually located in intersections. These links are coded with their characteristics such as speeds, length, capacities, and highway functional classification types. Once the network was created, it was checked to correct topology and final checking was done for accuracy by performing the "shortest paths module" between any two pairs of zones in the study area. Centroid connectors were created to link TAZ to the highway network. Figure (3) shows the 1987 highway network. The output of the trip distribution step is a P-A trip matrix that is subsequently converted to an O-D matrix. The O-D person trip matrix for internal trips estimated based on the friction factor matrix and the forecasted productions and attractions. The friction factor matrix estimated with the gamma function using default coefficients $(\mathrm{a}=1, \mathrm{~b}=0.3, \mathrm{c}=0.01)$ resulted in an average trip length of just 11 minutes. The friction factor formed $184 * 184$ matrices. Then, the impedance function must be calibrated and this represents an iteration process that entails selecting the impedance value (time) until the gravity model is brought to match the desired trip length frequency distribution. The calibrated impedance function results in coefficients $(a=2.75, b=0.2779, c=0.0199)$ and an average free-flow trip length of 12 minutes.

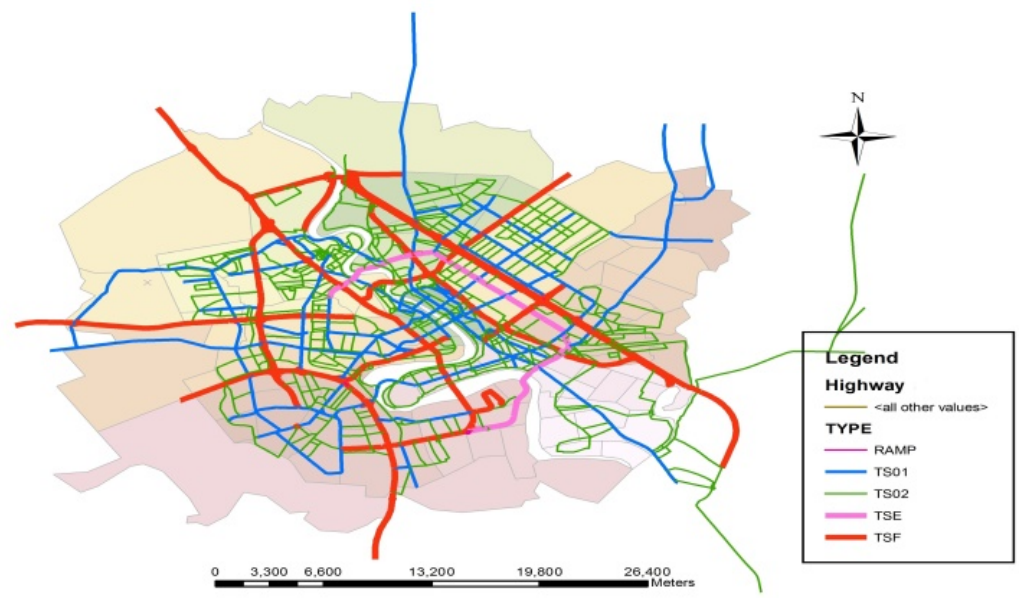

Figure 3 - The Baghdad Highway Network 1987 
Travel impedance skimmed from TAZ to TAZ zones based on the highway networks. Terminal Times represent the time for parking and walking at either end of a trip, terminal time added to all trips. Terminal time assumed 5 minutes in the CBD and 3 minutes in other areas to represent the network access times. The O-D person trip matrix for the year 1987 is represented in Figure (4).

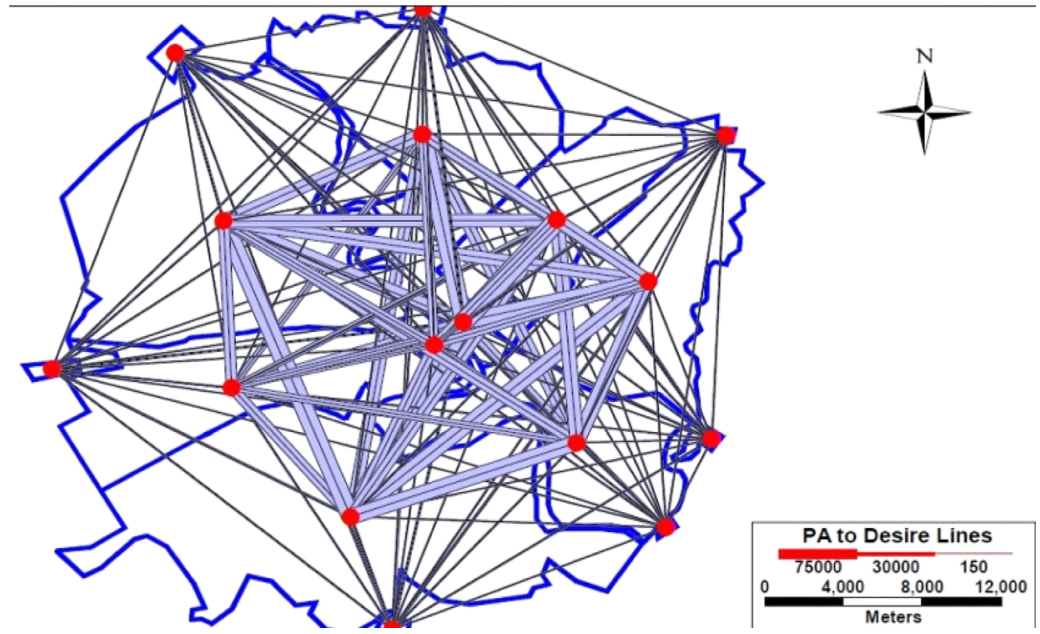

Figure 4 - The O-D Person Trips Matrix for 1987

\section{Data Collection}

The video photography method used in the traffic data collection in 2014 reflects the existing traffic characteristics of the study area. Traffic count was performed on 1/4/2014 from 7:00 AM to 3:00 PM by Video recording technique. The count was conducted on normal weekdays: Sunday, Monday and Tuesday, which represent the typical count days. The traffic data collected were extracted using visual inspection. The traffic flow data were recorded using video camera Canon EOS 5D Mark III. Special player software with a large zoom at any point on the screen was used to improve the efficiency of traffic counting. Three movements were considered for traffic count at each approach, which are the left turn, though, and right turn movements. The data were classified according to the type of vehicle and according to the direction. For each movement, traffic volume was classified into six categories by the vehicle type. The first category refers to private cars. The second category represents buses, inclusive of all vehicles with passenger capacity of 22 persons. The third category refers to minibuses. A truck is any vehicle with two or more axles and it represents the fourth category. The fifth category refers to bikes and motorcycles. The sixth one refers to taxi. The traffic count data were collected at the following main intersections in the study area: 
- Al-Huriyah Square

- Al Masbah Square

- Aqba Bin Nafi Square

- Grage Al Amana

- Cinema Al Bayda

- Al- Mushtal Square

- Al Gazila

- Al-Hamazia mosque at Shulah

\section{Estimation of O-D Matrix Based on Traffic Count 2014}

Estimation of the O-D matrix in 2014 using Nielsen's method requires a prior O-D matrix estimate, which is in our case represented by (the 1987 O/D matrix estimate), TAZ, and highway network. The TAZ of the year 2014 is consistent with the TAZ of 1987. The prior O-D matrix is in the unit of trip by person and converted to trip by vehicle using auto occupancy factors developed by Scott Wilson Kirkpatrick \& Partners. Reliable traffic count data will be used as the base in travel forecasting. The O-D matrix for 2014 will be estimated based on the collected traffic data. To achieve this process, the drawing of the highway network for the 2014-model requires modifications made in the 1987-model network to include the new roadway facilities constructed by the year 2014. The input data in the estimation of travel demand refer to traffic volumes on selected links. Traffic volumes on 30 selected links were entered and some of the link count data entered are shown in Table (1) by the Passenger Car Unit (PCU) in Peak Hour. Link counts must be entered as directional counts because of different flows on the two directions of a road. The aim of the model is to produce an O/D matrix consistent with the traffic count observed; the O-D estimation is an iterative procedure that stops once the estimated count values equal the observed values.

Table 1 - Observed Link Count on Selected Links

\begin{tabular}{cccc}
\hline Link ID & Type & AB-Preload & BA-Preload \\
\hline 1476 & TS01 & 2046 & 1234 \\
546 & TS01 & 1890 & 1468 \\
1445 & TS01 & 1442 & 1456 \\
772 & TSE & 1281 & 843 \\
634 & TS01 & 1212 & 1138 \\
\hline
\end{tabular}

Mode share developed by Asmael [3] was used in this study to split the vehicle volume and public transport. Public transport lines built based on the road network using the route system tool in TransCad [4] and the knowledge about the travel pattern between various zones in the study area were gathered from various sources. The 
O-D matrix results recommended the necessary measures for future scenarios. It was observed from the O-D matrix results that most O-D zones pair up with the high travel demand in peak hour as shown in Table (2).

Table 2 - Origin-Destination Zones with High Travel Demand Values

\begin{tabular}{llcc}
\hline Origin (Zone ID) & $\begin{array}{c}\text { Destination } \\
\text { (Zone ID) }\end{array}$ & $\begin{array}{c}\text { Person } \\
\text { Trips } \\
\text { in 2014 }\end{array}$ & $\begin{array}{c}\text { Description } \\
\text { (Origin-Destination) }\end{array}$ \\
\hline 321,322 & 111,112 & 1475 & Al-Shaab - Bab Moatham \\
321,322 & $113,121,122$ & 4142 & Al-Shaab- Bab -Alsharquie \\
442 & $431,432,433,434$ & 2970 & Al- Shulua - Kadhimiya \\
$911-915,921-927$ & $113,121,122$ & 7455 & Al-Karada - Bab -Alsharquie \\
$511-513,521-523$ & $113,121,122$ & 17300 & Sadir City - Bab -Alsharquie \\
$832,833,834$ & $113,121,122$ & 4704 & Bayaa - Bab -Alsharquie \\
$511-513,521-523$ & $431,432,433,434$ & 5651 & Sadir City - Kadhimiya \\
$742,734,726,724,741$ & $113,121,122$ & 9000 & New Baghdad- Bab -Alsharquie \\
$622-626,631$ & $113,121,122$ & 4750 & Al-Mansor - Bab -Alsharquie \\
\hline
\end{tabular}

The estimated O-D matrix of 2014 was assigned to the network to obtain the volumes on various links of the network. Figure 5 shows the assignment of vehicle flow and assignment of public transport for 2014. The obtained assignment results may be used in solving the existing transportation problems by adding a suitable sustainable mobility to Baghdad city. The public bus transport that suffers from severe road traffic congestion in urban areas represents the actual condition of the local public transport today. Thus, a new urban rail transit is recommended to provide sustainable solutions to the existing network problem, and it should be selected along the high passenger ridership routes that appeared in transit assignment results.

(a)
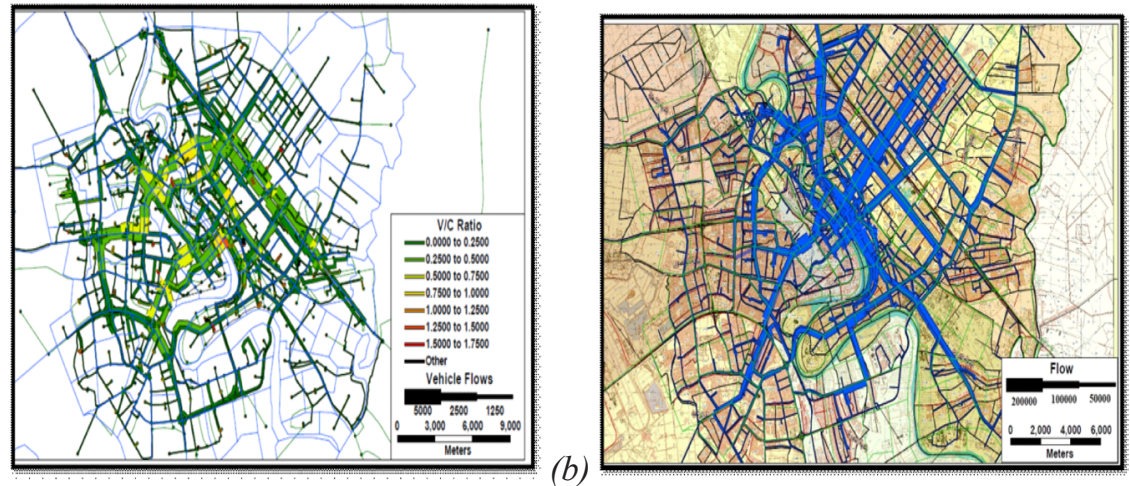

Figure 5 - Assignment Results 2014: (a) Highway Assignment (b) Transit Assignment. 


\section{Conclusions}

One important input to the transportation planning process is the Origin-Destination Matrix. In this study, the Origin-Destination matrix is estimated by Nielsen's method with the aid of Trans Cad, which method is a simple and cost-effective one, and reported good results. Reliable and various spatial properties of the O-D trip table estimated from traffic volume data are specified as an outcome of the study. Based on the O-D results, it has been observed that the highest travel demand is lying around the Ring Road No.2. The O-D of the heavy travel demand between a pair of zones is described in this study and, based on the assignment results, it is suggested that an urban transit system be introduced such as a Metro, Light rail transit, or Monorail based on the travel demand values in order to mitigate the congestion problem. It is recommended to introduce a new urban rail transit between Sadir City and Bab-Alsharquie to provide sustainable solutions to the existing congested network. The results of this study may be utilized to help transportation planners and local related agencies to make accurate decisions concerning transportation policies.

\section{Acknowledgment}

The authors wish to thank the staff in the Mayoralty of Baghdad - Central Organization for Statistics and Information Technology for their valuable support in providing the related historical data.

\section{Conflict of Interest}

The authors declare that they have no conflict of interest.

\section{References}

1. Almasri, Essam, and Mohammed Al-jazzar. (2013) TransCAD and GIS Technique for Estimating Traffic Demand and Its Application in Gaza City. 2013 (December): 242-250.

2. Anderson, Michael D. (2013) Using OD Estimation Techniques to Determine Freight Factors in a Medium Sized Community. Journal of Transportation Technologies 3 (1): 39-43. doi:10.4236/ jtts.2013.31004.

3. Asmael, Noor M. (2015) A GIS-Assisted Optimal Route Selection Based on Transportation Network Design (Baghdad Metro Case Study). Ph.D Dissertation, University of Baghdad.

4. Caliper Corporation. (2002) "Trans CAD 4.5 Help for Planning".

5. Cascetta, E. (1984) Estimation of trip matrices from traffic counts and survey data: a generalized least squares estimator. Transportation Research Part B: Methodological, 18(4), 289-299.

6. Chen, Anthony, Surachet Pravinvongvuth, Piya Chootinan, Ming Lee, and Will Recker. (2007) Strategies for Selecting Additional Traffic Counts for Improving O-D Trip Table Estimation. Transportmetrica 3 (3): 191-211. doi:10.1080/18128600708685673.

7. Ekowicaksono, I., F. Bukhari, and A. Aman. (2016) Estimating Origin-Destination Matrix of Bogor City Using Gravity Model. IOP Conference Series: Earth and Environmental Science 31 (1): 6-11. doi:10.1088/1755-1315/31/1/012021. 
8. Hamad, Khaled, and Ardeshir Faghri. (2003) An Innovative Methodology for Vehicular Demand Forecasting in Developing Countries. TRB 2003 Annual Meeting.

9. Holguín-Veras, J, I Sánchez-Díaz, and C A González-Calderón. (2013) Freight Demand Estimation from Secondary Sources. Case Study: Manhattan | Estimación de Demanda de Transporte de Carga a Partir de Fuentes Secundarias. Caso de Estudio: Manhattan." DYNA (Colombia). http://www. scopus.com/inward/record.url?eid=2-s2.0-84892391761\&partnerID=MN8TOARS.

10. Lei, P. (1998) A Linear programming method for synthesizing origin-destination (O-D) trip tables from traffic counts for inconsistent systems. Dissertation, Blacksburg, Virginia

11. Nielsen, O. (1993) A New Method for Estimating Trip Matrices from Counts. Institute of Roads, Traffic and Town Planning, the Technical University of Denmark.

12. Nielsen, Otto, and Christian Hansen. (2008) Updating Trip Matrices for Copenhagen Using Multiple Data Sources. Transportation Research, no. No.08-1164: 1-14.

13. Novačko, Luka, Ljupko Šimunović, and Davor Krasić. (2014) Estimation of Origin-Destination Trip Matrices for Small Cities. PROMET - Traffic\&Transportation 26 (5): 419-428. doi:10.7307/ ptt.v26i5.1501.

14. Scott Wilson Kirkpatrick and Partners. (1986) Baghdad Comprehensive Transportation Study. Amanat Al- Assima, Baghdad.

15. Swiss Consultants and DE consult. (1976) Baghdad Rapid Transit System, Feasibility study and Preliminary design of an integrated public transport system within the city of Baghdad. Ministry of Transport, Baghdad.

16. Tolouei, R., Álvarez, P., \& Duduta, N. (2015) Developing and verifying origin-destination matrices using mobile phone data: the llitm case. In European Transport Conference (Vol. 2015).

17. Verma, Ashish, and SL Dhingra. (2003) GIS for Identification of Demand-Oriented Urban Rail Transit Corridor. Map India Conference, no. 2003: 1-15. http://www.gisdevelopment.net/ application/Utility/transport/mi03091pf.htm.

18. Wu, Zixiao, Bo Shen, and Dawei Lv. (2012) Study on the Transit Network Evaluation Method Based on the Transit Ridership Model. Procedia - Social and Behavioral Sciences 43 (8610): 428-434. doi:10.1016/j.sbspro.2012.04.116.

19. Yang, H., Sasaki, T., Iida, Y., \& Asakura, Y. (1992). Estimation of origin-destination matrices from link traffic counts on congested networks. Transportation Research Part B: Methodological, 26(6), 417-434. 